\title{
Tingkat Adopsi Teknologi Pengelolaan Tanaman Terpadu (PTT) di Kabupaten Seluma
}

\section{Adoption Level of Integrated Plant Management Technology (IPMT) in Seluma District}

\author{
Merna Ayu Sulastri ${ }^{1, *}$, Satria Putra Utama ${ }^{2}$, Ketut Sukiyono ${ }^{2}$
}

${ }^{1}$ Mahasiswa Program Studi Pasca Sarjana Agribisnis, Fakultas Pertanian, Universitas Bengkulu, Bengkulu 38371, Indonesia ${ }^{2}$ Program Studi Pasca Sarjana Agribisnis, Fakultas Pertanian, Universitas Bengkulu, Bengkulu 38371, Indonesia

${ }^{*}$ E-mail Korespondensi: mernaayulestari@gmail.com

Diterima: 7 Juni 2021 | Disetujui: 28 Agustus 2021 | Publikasi Online: 2 Februari 2022

\begin{abstract}
Integrated Plant Management Technology (IPMT) is currently applied by farmers in the village of Rimbo Kedui Seluma District. In the context of agricultural technology adoption, farmers' perception of innovation characteristics becomes very important because it becomes the basis of decision making to accept or reject an innovation. The purposes of this research were to analyze the perception of farmers on innovation, the level of adoption of innovation in farmers in understanding the technology component contained in Integrated Plant Management, analyzing what variables affect the level of Technology adoption on rice farmers in Seluma district. The method used in this study was the method of analysis of SEM (Structural Equation Model). Variables used were the characteristics of internal farmers, the perception and level of adoption of integrated plant management technology. The respondents used in this study were 140 people. The results of the research showed that farmers' perception of integrated plant management technology was in medium category, farmer adoption rate was in medium category, and variable that affects farmers adopt plant management technology was integrated characteristics of the farmer's internal at 0.44 and the perception of farmers at -0.11 , internal characteristics of farmers through the perception of farmers that is equal to 0.00 .
\end{abstract}

Keywords: Adoption level, innovation, IPMT, perception

\section{ABSTRAK}

Teknologi Pengelolaan tanaman Terpadu (PPT) saat ini sudah diterapkan oleh petani pada Kelurahan Rimbo Kedui, Kecamatan Seluma Selatan, Kabupaten Seluma. Dalam konteks adopsi teknologi pertanian, persepsi petani terhadap karakteristik inovasi menjadi sangat krusial sebab menjadi dasar pembuatan keputusan buat menerima atau menolak sebuah penemuan atau inovasi. Tujuan penelitian ini adalah menganalisis persepsi petani terhadap inovasi, tingkat adopsi inovasi petani pada memahami komponen teknologi yang ada dalam pengelolaan tanaman terpadu; serta menganalisis variabel yang mempengaruhi taraf adopsi teknologi pada petani padi sawah Kabupaten Seluma. Metode yang digunakan pada penelitian ini adalah metode analisis SEM (Structural Equation Model). Variabel yang dipergunakan ialah variabel karakteristik internal petani, persepsi dan taraf adopsi teknologi pengelolaan tanaman terpadu. Responden yang digunakan pada penelitian ini artinya sebesar 140 orang. Hasil penelitian menunjukkan persepsi petani terhadap teknologi pengelolaan tanaman terpadu berada pada kategori sedang, tingkat adopsi petani berada pada kategori sedang dan variabel yang mempengaruhi petani mengadopsi teknologi pengelolaan tanaman terpadu adalah karakteristik internal petani sebesar 0,44 dan persepsi petani sebesar -0,11, karakteristik internal petani melalui persepsi petani, yaitu sebesar 0,00 .

Kata kunci: Inovasi, persepsi, PTT, tingkat adopsi

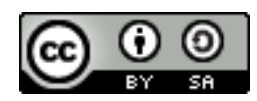

Content from this work may be used under the terms of the Creative Commons Attribution-ShareAlike

4.0 International. Any further distribution of this work must maintain attribution to the author(s) and the title of the work, journal citation and DOI.

Published under Department of Communication and Community Development Science, IPB University and in association with Perhimpunan Ahli Penyuluhan Pembangunan Indonesia.

E-ISSN: 2442-4110 | P-ISSN: 1858-2664 


\section{PENDAHULUAN}

Pemenuhan kebutuhan pangan di Indonesia saat ini menjadi permasalahan penting yang harus diselesaikan oleh pemerintah Indonesia. Hal ini dikarenakan pangan memiliki pengaruh pada kualitas sumber daya manusia. Pangan masyarakat Indonesia mayoritas adalah beras. Namun permasalahan pada komoditi ini adalah rendahnya kualitas dan kuantitas hasil produksi usahatani padi, sehingga pemerintah harus mengimpor dari luar negeri. Oleh sebab itu, peningkatan produksi usahatani menjadi penting yang salah satunya adalah dengan penerapan inovasi yang berkelanjutan. Artinya, teknologi inovasi tersebut harus ramah lingkungan fisik maupun sosial (Departemen Pertanian 2016). Teknologi inovasi yang dianjurkan oleh pemerintah adalah teknologi Pengelolaan Tanaman Terpadu (PTT). Teknologi PTT dimaksud harus memperhatikan beberapa kriteria, yaitu (a) secara teknik bisa diterapkan, (b) dilihat dari ekonomi memberi keuntungan, dan (c) tidak bertentangan dengan norma yang berlaku serta ramah lingkungan.

Inovasi PTT merupakan teknologi yang dirakit secara partisipatif bersama petani, melalui pendekatan inovatif dan dinamis. Paket teknologi terdiri dari penggunaan benih varietas unggul, benih bermutu dan berlabel, penggunaan bahan organik, pengoptimalan jumlah populasi tanaman, pemupukan didasarkan pada kebutuhan tanaman, pengendalian Organisme Pengganggu Tanaman (OPT), pengolahan tanah sesuai musim, bibit yang digunakan muda dan $<21$ hari, per rumpun bibit ditanam sebanyak 1-3 batang, mengefektifkan dan mengefisienkan pengairan, penyiangan menggunakan landak atau gasrok, serta pemanenan dan perontokan gabah tepat waktu (Badan Litbang Pertanian 2010). Teknologi PTT telah diintroduksikan pemerintah di Provinsi Bengkulu termasuk di Kabupaten Seluma, khususnya di Kecamatan Seluma Selatan dan Kelurahan Rimbo Kedui. Pada tahun 2010, luas lahan keseluruhan Kecamatan Seluma Selatan seluas 835,64 ha, dimana Kelurahan Rimbo Kedui memiliki peruntukan lahan sawah tertinggi yaitu seluas 505,00 ha (60,31\%) sedangkan peruntukan lainnya seluas 330,64 ha (BPS Kabupaten Seluma 2018), dengan lokasi penelitian merupakan sentra penghasil padi di Kabupaten Seluma yang bertepatan di Kelurahan Rimbo Kedui.

Kabupaten Seluma memiliki potensi pertanian yang besar, terutama pada komoditi padi sawah. Kondisi saat ini, Kabupaten Seluma dihadapkan dengan permasalahan, alih fungsi lahan yang berakibat pada pengurangan luas lahan sawah, serta produktivitas yang dicapai petani masih relatif rendah 3,50 ton/ha lebih rendah dari produktivitas Kabupaten Seluma yang mencapai 4,01 ton/ha. Introduksi dan adopsi teknologi PTT padi sawah di Kabupatren Seluma diharapkan dapat mempercepat dan meningkatkan produktivitasnya (Yartiwi, Damiri, and Wawan Eka Putra 2012). Karakteristik inovasi menjadi sangat penting dalam mempengaruhi persepsi petani. Salah satu argumennya adalah persepsi ini sering menjadi dasar dalam pengambilan keputusan petani untuk menerima sebuah inovasi atau menolaknya. Artinya, jika teknologi memiliki karakteristik yang diinginkan petani, maka inovasi akan mudah diterima, demikian sebaliknya. Karakteristik ini, menurut (Rogers 2003) meliputi komponen kerumitan (complexity), keuntungan relatif (comparative advantage), keteramatan (observability), kesesuaian (compatability), dan ketercobaan (trialibility). Sementara, (Davis 1989) mengelompokkannya menjadi variabel persepsi kemudahan dalam aplikasi (perceived ease of use) dan kegunaan yang dirasakan (perceived usefulness).

Aktivitas penyebaran informasi baik yang dilakukan oleh penyuluh maupun kelompok tani juga merupakan salah satu faktor penentu kecepatan adopsi inovasi. Salah satu penjelasannya yang diberikan (Wahyu 2010), adalah adopsi dapat berproses secara lebih cepat apabila dua agen ini mampu dan dapat berkomunikasi secara efektif serta terampil menggunakan saluran komunikasi. Artinya, jika penyuluh dan kelompok tani dalam menawarkan inovasi teknologi makin sering berkomunikasi, proses adopsi dapat dicapai makin cepat. Lebih jauh (Anggraeni, Dumasari, and Utami 2015) menyebutkan peran penyuluh pertanian sangat diperlukan untuk memberikan informasi mengenai kesesuaian spesifik lokasi dengan inovasi teknologi pertanian terbaru yang akan diberikan kepada petani, sehingga petani akan lebih mudah memahami dan untuk mengadopsi atau tidak. Studi tentang adopsi teknologi telah banyak berkembang. Penelitian-penelitian ini telah banyak menjawab pertanyaan-pertanyaan penelitian yang terkait dengan faktor-faktor penentu adopsi untuk memahami apa yang menyebabkan perbedaan dalam tingkat adopsi dan apa kendala untuk adopsi inovasi. Beberapa kajian, diantaranya adalah (Beedell and Rehman 2000; Caswell and Zilberman 1985; Nuthall 2001; Rahm and Huffman 1984; Sharma, Bailey, and Fraser 2011), menganalisis perilaku adopsi teknologi di bidang pertanian, yang sebagian berfokus pada faktor-faktor yang mempengaruhinya. Secara umum, penelitian ini menyimpulkan bahwa tingkat adopsi terjadi pada 
kecepatan atau tingkat yang berbeda tergantung pada biaya teknologi, kerangka kerja regulasi, karakteristik sosial-ekonomi, pengaruh teman sebaya, sikap terhadap inovasi, dan persepsi risiko. Berangkat dari fenomena adopsi teknologi PTT yang terjadi di Kabupaten Seluma dan kajian pustaka yang dilakukan, penelitian ditujukan untuk menjawab pertanyaan-pertanyaan yang terkait dengan; persepsi petani terhadap inovasi PTT padi sawah; tingkat adopsi inovasi petani pada teknologi PTT padi sawah; dan faktor-faktor yang mempengaruhi tingkat adopsi teknologi PTT, sangat bijak untuk dilakukan.

\section{METODE}

Penelitian ini mencakup topik mengenai tingkat adopsi teknologi pengelolaan tanaman terpadu. Lokasi studi ditentukan secara sengaja (purposive) yang merupakan sentra produksi padi Sawah di Kelurahan Rimbo Kedui, Kecamatan Seluma Selatan, Kabupaten Seluma. Responden dalam penelitian ini adalah sebanyak 140 orang. Penentuan responden dilakukan dengan menggunakan Tabel Krejcie dan Morgan dari jumlah populasi sebanyak 220 orang. Data dianalisis dengan analisis kuantitatif, selanjutnya statistik deskriptif frequensi digunakan untuk menganalisis tingkat adopsi dan persepsi petani terhadap teknologi PTT. Uji validitas dan realibilitas faktor yang mempengaruhi tingkat adopsi dianalisis dengan analisis faktor konfirmatori (Confirmatory Factor Analysis/CFA). Dalam hal ini, model Structural Equation Modelling (SEM) seperti yang disarankan oleh (Kline 2011) diaplikasikan untuk menjawab hubungan struktural antara variabel yang diukur.

SEM adalah teknik analisis statistik multivariat yang terdiri dari analisis faktor, analisis jalur, dan analisis regresi berganda, digunakan untuk menganalisis hubungan struktural antara variabel yang diukur dan konstruk laten. Dua komponen dasar yang mencirikan SEM adalah model jalur, yang berhubungan independen dengan variabel dependen, bahkan ketika variabel dependen menjadi variabel independen dalam hubungan lain, dan model pengukuran yang memungkinkan analis buat memakai beberapa variabel atau indikator buat variabel independen atau dependen tunggal (Hair et al. 2006). Lebih lanjut, (Ghozali 2008) menyebutkan bahwa SEM atau model persamaan struktural merupakan turunan kedua teknik analisis multivariate yang memungkinkan buat menguji pengaruh antar variabel recursive juga non-recursive buat dapat menggambarkan secara komprehensif model. Dalam penelitian ini, adopsi PTT, menjadi variabel dependen, diasumsikan sebagai fungsi berdasarkan: umur (AGE), tingkat pendidikan formal (EDU), pengalaman usahatani (EXP), jumlah tanggungan keluarga (NF), dan Status Kepemilikan Lahan (LOF) (Adawiyah 2017). Persepsi petani (Davis 1989) terhadap teknologi PTT yaitu: keuntungan relatif, kesesuaian, tingkat kerumitan, sanggup diujicobakan, dapat diamati (Ismilaili, Purnaningsih, and Asngari 2015). Tingkat adopsi penemuan PTT padi sawah diukur dari Varietas Unggul Baru, benih bermutu dan berlabel, pemberian bahan organik secara terstruktur, pengaturan populasi tumbuhan, pemupukan sinkron kebutuhan tanaman dan status hara tanah, dan pengendalian OPT memakai pendekatan PHT.

Selanjutnya, factor confirmatori analysis dilakukan menggunakan program LISREL 8,80 for Windows. Dalam pengambilan keputusan peneliti memakai kriteria penerimaan standardized loading factor menurut masing-masing variabel teramati $(\lambda)>0,50, \mathrm{t}$-value standardized solution $>1.96$, Construct Reliability (CR) $>0.70$, dan goodness-of-fit menggunakan $p$-value yang semakin kecil dan RMSEA $\leq 0,08$ (Rigdon and Carl E Ferguson 1991).

\section{HASIL DAN PEMBAHASAN}

\section{Persepsi Petani Terhadap Teknologi PTT}

Persepsi petani di lokasi penelitian dalam penggunanaan teknologi Pengelolaan Tanaman Terpadu (PTT) dapat dilihat dengan indikator dominan pada tiap kategori pada Tabel 1 (Halaman 78).

Persepsi keuntungan relatif terhadap inovasi PTT berada pada kategori sedang dengan persentase 64\%. Persepsi petani berdasarkan kesesuain inovasi terhadap kondisi lahan yang ada di Rimbo Kedui, yaitu berada pada kategori sedang dengan persentase $51 \%$. Selanjutnya, disusul menggunakan persepsi petani terhadap karakter persepsi kerumitan menggunakan teknologi PTT pada kategori sedang dengan persentase 65\%. Pada karakter penemuan bisa diuji coba dan bisa diamati berada dalam kategori baik persentase masing-masing 27\% dan 34\%. (Tabel 1). Artinya, persepsi petani terhadap sifat teknologi pengelolaan tanaman terpadu (PTT) pada Kelurahan Rimbo Kedui berada rata rata dalam kategori sedang. Berbeda menggunakan penelitian yang dilakukan (Fachrista and Mamik 2014), 
menjelaskan bahwa persepsi petani tentang penggunaan teknologi pengelolaan tamanan terpadu padi sawah adalah positif. Hal ini berkenaan dengan meningkatnya produksi padi petani, tentunya penemuan teknologi tadi gampang buat diterapkan, sesuai dengan nilai-nilai sosial, dan sinkron terhadap kebutuhan petani.

Tabel 1. Persepsi Petani terhadap PTT

\begin{tabular}{clccccc}
\hline No. & Kategori & $\begin{array}{c}\text { Keuntungan } \\
\text { Relatif } \mathbf{( \% )}\end{array}$ & $\begin{array}{c}\text { Kesesuaian } \\
(\mathbf{\%})\end{array}$ & $\begin{array}{c}\text { Kerumitan } \\
\mathbf{( \% )}\end{array}$ & $\begin{array}{c}\text { Dapat Diuji } \\
\text { Coba (\%) }\end{array}$ & $\begin{array}{c}\text { Dapat } \\
\text { Diamati } \\
(\boldsymbol{\%})\end{array}$ \\
\hline 1. & Sangat Buruk & 0 & 0 & 0 & 16 & 6 \\
2. & Buruk & 8 & 14 & 11 & 26 & 14 \\
3. & Sedang & 64 & 51 & 65 & 19 & 24 \\
4. & Baik & 25 & 35 & 21 & 27 & 34 \\
5. & Sangat Baik & 3 & 0 & 4 & 12 & 21 \\
\hline
\end{tabular}

Sumber: Data Primer diolah, 2019

\section{Tingkat Adopsi Teknologi PTT}

Tingkat adopsi teknologi pengelolaan tanaman terpadu dapat dijelaskan seperti pada Tabel 2 berdasarkan uji deskriptif frekuensi.

Tabel 2. Persentase Tingkat Adopsi Petani

\begin{tabular}{llcccccc}
\hline No. & Kategori & $\begin{array}{c}\text { Varietas } \\
\text { Unggul } \\
\text { Baru }\end{array}$ & $\begin{array}{c}\text { Benih } \\
\text { Bermutu }\end{array}$ & $\begin{array}{c}\text { Pemberian } \\
\text { bahan } \\
\text { organik }\end{array}$ & $\begin{array}{c}\text { Pengaturan } \\
\text { populasi } \\
\text { tanaman }\end{array}$ & $\begin{array}{c}\text { Pemupu- } \\
\text { kan }\end{array}$ & $\begin{array}{c}\text { Pengen- } \\
\text { dalian OPT }\end{array}$ \\
\cline { 3 - 8 } & $\%$ & $\%$ & $\%$ & $\%$ & $\%$ & $\%$ \\
\hline 1. & Sangat Rendah & 1,42 & 1,42 & 3,57 & 2,86 & 1,43 & 0,71 \\
2. & Rendah & 6,42 & 4,28 & 19,29 & 10,00 & 4,29 & 10,00 \\
3. & Sedang & 11,42 & 7,14 & 32,86 & 20,00 & 25,71 & 24,29 \\
4. & Tinggi & 26,42 & 39,28 & 35,00 & 19,29 & 40,00 & 32,14 \\
5. & Sangat Tinggi & 54,28 & 48,85 & 9,29 & 47,86 & 28,57 & 33,86 \\
\hline
\end{tabular}

Sumber: Data Primer diolah, 2019

Tingkat adopsi petani terhadap komponen teknologi pengelolaan tanaman terpadu menunjukkan ratarata berada pada kategori tinggi dan sangat tinggi. Persepsi petani terhadap komponen PTT VUB (Varietas Unggul Baru) tergolong pada kategori sangat tinggi yaitu sebesar 54,28 \%, komponen teknologi benih bermutu tergolong dalam kategori sangat tinggi yaitu sebesar 48,85\%, selanjutnya teknologi pemberian bahan organik tergolong pada kategori tinggi, pengaturan populasi tanaman tergolong dalam kategori sangat tinggi dengan persentase $47,86 \%$, teknologi penggunaan pupuk tergolong dalam kategori tinggi dengan persentase $40 \%$, dan yang terakhir teknologi pengendalian OPT berada pada kategori sangat tinggi dengan persentase 33,86\%. Artinya, dari 6 komponen teknologi dasar yang ada pada teknologi pengelolaan tanaman terpadu rata-rata berada pada tingkat adopsi sangat tinggi.

Penelitian yang dilakukan oleh (Fachrista and Mamik 2014), menjelaskan bahwasanya tingkat adopsi pengelolaan tanaman terpadu pada Desa Labu, Kecamatan Puding Besar, Kabupaten Bangka tergolong masih rendah dengan persentase $48 \%$. Rendahnya adopsi teknologi di desa tersebut disebabkan oleh kurangnya informasi petani mengenai teknologi yang dianjurkan oleh pemerintah melalui penyuluh, sehingga petani masih banyak yang belum mengadopsi teknologi inovasi tersebut.

Menurut penelitian yang dilakukan (Ismilaili et al. 2015) adopsi penemuan teknologi PTT pada Kecamatan Leuwiliang Kabupaten Bogor termasuk pada kategori tinggi, hal ini menandakan bahwa penemuan pengelolaan tumbuhan terpadu (PTT) diterima baik petani. Persepsi petani terhadap komponen teknologi penemuan PTT padi sawah pada Kecamatan Leuwiliang Kabupaten Bogor termasuk pada kategori sangat tinggi. Sedangkan dari penelitian (Pello, 2019) terungkap bahwa pada Kecamatan Kupang Timur, variabel Y (inovasi teknologi budidaya tanaman padi) berada pada kategori sedang $(78,33 \%)$. Hal ini dipandang berdasarkan aspek penyebaran penemuan teknologi 
budidaya tanaman padi dari aspek partisipasi petani sebesar $66,17 \%$ saja dan oleh penyuluh sebesar $74,50 \%$.

\section{Uji Distribusi Data}

Sebelum melakukan uji dengan menggunakan SEM tahap awal yang harus dipenuhi adalah dengan memastikan data yang digunakan sudah terdistribusi normal atau tidak. Cara yang dilakukan dengan melihat nilai angka cr kurtosis (puncak) atau cr skewness (kemiringan) berada diantara -2,58 sampai $+2,58$ (Supriyati 2013). Nilai cr kurtosis yang terlihat pada Tabel 3 terlihat adalah sebesar 0,079, artinya data yang digunakan sudah memenuhi kriteria uji normalitas dengan demikian Analisis SEM dapat dilakukan.

Tabel 3. Uji Normalitas

\begin{tabular}{lccccc}
\hline Variabel Manifes & Variabel & Minimum & Maksimum & \multicolumn{2}{c}{$\begin{array}{c}\text { Skewness dan } \\
\text { Kurtosis }\end{array}$} \\
& & & & Chi-Square & P-Value \\
\hline \multirow{2}{*}{ Persepsi petani } & X1.1 & 2,000 & 5,000 & 11,566 & 0,083 \\
terhadap PTT & X1.2 & 2,000 & 4,000 & 13,040 & 0,698 \\
& X1.4 & 2,000 & 5,000 & 12,062 & 0,102 \\
Karakteristik & 1,000 & 5,000 & 32,923 & 0,097 \\
Internal Petani & X2.1 & 1,000 & 5,000 & 7,413 & 0,064 \\
& X2.2 & 1,000 & 5,000 & 6,268 & 0,051 \\
& X2.3 & 1,000 & 5,000 & 11,530 & 0,133 \\
& X2.4 & 2,000 & 5,000 & 8,727 & 0,576 \\
Komponen PTT & Y1 & 2,000 & 5,000 & 1,103 & 0,065 \\
& Y2 & 2,000 & 5,000 & 62,495 & 0,057 \\
& Y3 & 2,000 & 5,000 & 6,122 & 0,183 \\
& Y4 & 2,000 & 5,000 & 3,391 & 0,075 \\
\hline Multivarian & Y5 & 1,000 & 5,000 & 7,383 & 0,091 \\
\hline
\end{tabular}

Sumber: Analisis Data Primer, 2019

Tabel 3 juga menjelaskan variabel-variabel laten dan variabel-variabel manifes yang termaktub didalamnya, yaitu: (1) Variabel laten persepsi petani terhadap teknologi PTT, terdiri dari variabelvariabel manifes, yaitu; keuntungan relatif (X1.1), kesesuaian (X1.2), kerumitan (X1.3), dapat diujicoba (X1.4), dapat diamati (X1.5). (2) Variabel laten karakteristik internal petani, terdiri dari: umur (X2.1), pendidikan formal (X2.2), pengalaman usaha tani (X2.3), jumlah tanggungan keluarga (X2.4). (3) Variabel laten, adopsi komponen PTT, terdiri dari variabel manifes, yaitu: varietas unggul baru (Y1), benih bermutu (Y2), pemberian bahan organik (Y3), pengaturan populasi tanam (Y4), pemupukan berdasarkan kebutuhan (Y5), pengendalian OPT (Y6).

\section{Analisis Konfirmatori Variabel Persepsi}

Uji konfirmatori variabal ini dilakukan untuk melihat nilai loading faktor pada setiap variabel laten yang diuji. Gambar 1 adalah hasil analisis yang dilakukan pada variabel laten persepsi petani terhadap teknologi PTT.

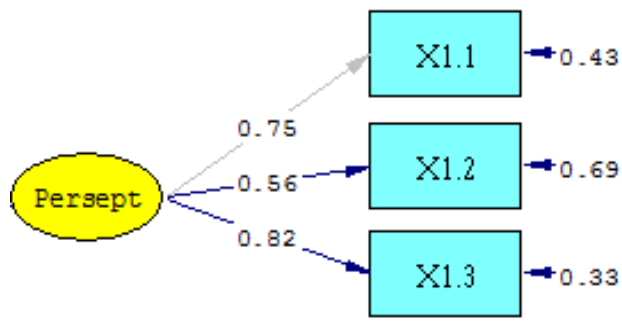

Gambar 1. Nilai Muatan Factor Order CFA

Hasil CFA yang dilakukan menunjukkan hasil output yang menyatakan bahwasanya semua indikator yang digunakan untuk melihat persepsi petani terhadap teknologi PTT dapat menggambarkan dengan 
baik variabel laten persepsi dalam penelitian ini. Nilai loading factor dari semua indikator memiliki nilai $>0,50$ yang berarti nilai setiap indikator dapat menggambarkan Variabel Laten Persepsi. Indikator dengan nilai loading factor paling baik adalah indikator kerumitan dengan nilai loading factor 0,82 , kemudian disusul dengan indikator keuntungan relatif dengan nilai loading factor 0,75 . Nilai paling kecil adalah pada indikator kesesuaian dengan nilai loading factor 0,56. Sesuai menurut (Hair et al. 2006) dalam (Riadi 2018) yang menyatakan bahwasanya nilai loading factor lebih besar dari 0,5 atau 0,7 dapat untuk menyimpulkan variabel manifesnya valid.

Secara keseluruhan dari tiga variabel manifes yang terpilih dapat disimpulkan bahwa hubungan indikator-indikator terhadap variabel persepsi petani pada teknologi PTT dapat dikategorikan baik, karena memiliki nilai composite realiability 0,75 yang $>0,7$. Dimana kriteria nilai composite realiability yang baik adalah >0,7 dan nilai Variance Extracted (VE) yaitu 0,51.

Tabel 4. Hasil Analisis konfirmatori Konstruk Persepsi Petani terhadap Teknologi PTT

\begin{tabular}{cccccccc}
\hline $\begin{array}{c}\text { Variabel } \\
\text { Manifes }\end{array}$ & $\begin{array}{c}\text { Standarized } \\
\text { Loading Factor }\end{array}$ & $\begin{array}{c}\text { Standard } \\
\text { Error }\end{array}$ & $\mathbf{R 2}$ & t. value & Keterangan & $\begin{array}{c}\text { CR } \\
(>\mathbf{0 , 7 0})\end{array}$ & VE \\
\hline X1.1 & 0,75 & 0,43 & 0,69 & 8,43 & Valisitas Baik & 0,75 & 0,51 \\
X1.2 & 0,56 & 0,69 & 0,57 & 6,38 & Valisitas Baik & 0,5 & \\
X1.3 & 0,82 & 0,33 & 0,98 & 8,76 & Valisitas Baik & & \\
\hline
\end{tabular}

Sumber: Analisis data primer diolah, 2019

Berdasarkan hasil analisis yang telah dilakukan, diketahui ada beberapa kriteria indeks yang dapat menguji model yang digunakan fit atau tidak. Dalam penelitian ini dilihat 8 indeks yang menyatakan bahwa model yang digunakan fit (Tabel 5).

Tabel 5. Uji Goodness of Fit Index

\begin{tabular}{lccc}
\hline Goodness of fit Index & Cut-off value & Hasil Model & Keterangan \\
\hline$\chi 2-$ Chi-square & Diharapkan kecil & $6.79(\mathrm{P}=0.033)$ & Good Fit \\
Df & $>0,00$ & 32 & Good Fit \\
GFI & $\geq 0.90$ & 0.980 & Good Fit \\
NFI & $>0,90$ & 0.940 & Good Fit \\
CFI & $>0,90$ & 0.960 & Good Fit \\
IFI & $>0,90$ & 0.960 & Good Fit \\
RMSEA & $\leq 0,08$ & 0.075 & Good Fit \\
RMR & $<0,05$ & 0.030 & Good Fit \\
\hline
\end{tabular}

Sumber: Analisis data primer diolah, 2019

Menurut (Riadi 2013) jika dari delapan indeks yang dipakai telah fit, maka bisa disimpulkan bahwa model relatif fit. Berbeda dengan hasil penelitian (Sudjarmoko, Listyati, and Hasibuan 2013) menjelaskan bahwa menurut beberapa kriteria uji fit model yang dibangun belum memenuhi kriteria goodness of fit sebagaimana syarat yang telah ditentukan. Terdapat dua kriteria (RMSEA dan GFI) masuk kategori marginal fit dari enam kriteria yang diuji, sedangkan empat kriteria lainnya tidak masuk kriteria fit. Oleh karena itu, respesifikasi harus dilakukan terhadap model yang dipakai.

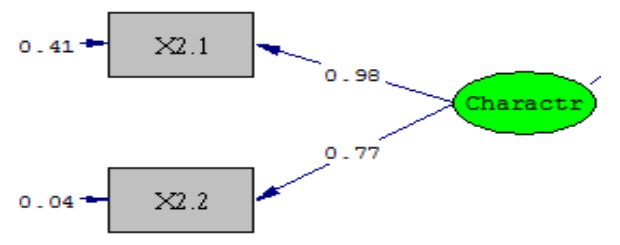

Gambar 2. Nilai Muatan Factor $2^{\text {nd }}$ Order CFA

Hasil CFA menyatakan bahwa semua indikator yang digunakan pada model kedua setelah dilakukan penghapusan variabel manifest yang tidak berpengaruh dan tidak dapat menggambarkan variabel laten karakteristik internal petani, menunjukkan nilai loading factor yang baik. Nilai loading factor dari semua indikator memiliki nilai $>0,05$ yang berarti nilai setiap indikator dapat menggambarkan variabel laten (karakteristik internal). Indikator dengan nilai loading factor paling baik adalah indikator dengan 
nilai loading factor 0,98 pada indikator pendidikan formal yang diikuti dengan nilai loading faktor umur petani dengan nilai loading 0,77 (Tabel 6).

Secara keseluruhan dapat disimpulkan bahwa hubungan indikator-indikator terpilih terhadap variabel karakteristik internal petani dapat dikategorikan baik, karena memiliki nilai composite realiability 0,79 yang lebih dari 0,7. Penelitian lain yang dilakukan oleh (Farid, Romadi, and Witono 2018) bahwasanya faktor pendidikan tidak berpengaruh dikarenakan rata-rata pendidikan petani di Desa Sukosari didominasi oleh petani yang hanya menyelesaikan pendidikan formal setaraf dengan sekolah dasar. Seseorang dengan pendidikan tinggi pada umumnya, orang tersebut akan semakin luas pengetahuannya.

Tabel 6. Hasil Analisis konfirmatori Konstruk Eksogen Karakteristik Internal Petani

\begin{tabular}{cccccccc}
\hline $\begin{array}{c}\text { Variabel } \\
\text { Manifest }\end{array}$ & $\begin{array}{c}\text { Standarized } \\
\text { Loading Factor }\end{array}$ & $\begin{array}{c}\text { Standard } \\
\text { Error }\end{array}$ & $\mathbf{R 2}$ & t. value & Keterangan & $\begin{array}{c}\text { CR } \\
(>\mathbf{0 , 7 0})\end{array}$ & $\begin{array}{c}\text { VE } \\
(>\mathbf{0 , 4 0})\end{array}$ \\
\hline X2.1 & 0,77 & 0,41 & 0,46 & 6,79 & Valisitas Baik & 0,79 & 0,50 \\
X2.2 & 0,98 & 0,04 & 01,24 & 8,20 & Valisitas Baik & & \\
\hline
\end{tabular}

Sumber: Hasil analisis data primer yang diolah, 2019

Berdasarkan hasil analisis yang telah dilakukan, diketahui ada beberapa kriteria indeks yang dapat menguji model yang digunakan fit atau tidak. Dalam penelitian ini dilihat 9 indeks yang menyatakan bahwa model yang digunakan fit (Tabel 7).

Tabel 7. Uji Model Goodness of Fit Test Konfirmatori Konstruk Eksogen Karakteristik Internal Petani

\begin{tabular}{lccc}
\hline Goodness of fit Index & Cut- off value & Hasil Model & Keterangan \\
\hline$\chi 2-$ Chi- square & Diharapkan kecil & 1.97 & Fit \\
Df & $>0,00$ & 2,00 & Fit \\
GFI & $\geq 0.90$ & 0.99 & Fit \\
AGFI & $\geq 0.90$ & 0.96 & Fit \\
TLI/NNFI & $>0,90$ & 1.00 & Fit \\
NFI & $>0,90$ & 0.98 & Fit \\
CFI & $>0,90$ & 1.00 & Fit \\
RMSEA & $\leq 0,08$ & 0.012 & Fit \\
RMR & $<0,05$ & 0.034 & Fit \\
\hline
\end{tabular}

Sumber: Hasil analisis data primer yang diolah, 2019

\section{Analisis Konfirmatori Konstruk Teknologi PTT}

Hasil uji CFA untuk semua indikator yang digunakan pada model kedua setelah dilakukan penghapusan variabel manifest yang tidak berpengaruh pada variabel komponen teknologi PTT (Y) menunjukkan nilai loading faktor yang baik. Nilai loading faktor dari semua indikator memiliki nilai $>0,05$ yang berarti nilai setiap indikator dapat menggambarkan variabel laten (persepsi). Indikator dengan nilai loading paling baik adalah indikator dengan nilai loading 1,00 untuk Y2, kemudian disusul dengan indikator keuntungan relatif dengan nilai loading 0,79 untuk Y6, 0,78 untuk Y3, 0,75 untuk nilai loading variabel manifest Y1. Nilai paling kecil adalah pada indikator Y4 dengan nilai loading 0,71 .

Tabel 8. Hasil Analisis Konfirmatori Konstruk Endogen Komponen Teknologi PTT

\begin{tabular}{ccccccccc}
\hline $\begin{array}{c}\text { Variabel } \\
\text { Manifest }\end{array}$ & $\begin{array}{c}\text { Koefisien. } \\
\text { Reg }\end{array}$ & $\begin{array}{c}\text { Error. } \\
\text { var }\end{array}$ & $\begin{array}{c}\text { Standar } \\
\text { Error }\end{array}$ & R2 & t.hit & Keterangan & $\begin{array}{c}\text { CR } \\
(>\mathbf{0 . 7 0})\end{array}$ & $\begin{array}{c}\text { VE } \\
(>\mathbf{0 . 4 0})\end{array}$ \\
\hline Y1 & $0.75 *$ PTT & 0.43 & 0.073 & 0.57 & $10.38^{* *}$ & Validitas baik & & \\
Y2 & $1.00 *$ PTT & 0.00 & 0.054 & 1.00 & $12.78^{* *}$ & Validitas baik & & \\
Y3 & $0.78 *$ PTT & 0.40 & 0.060 & 0.60 & $9.86 * *$ & Validitas baik & 0.90 & 0.65 \\
Y4 & $0.71 *$ PTT & 0.49 & 0.067 & 0.50 & $8.92 * *$ & Validitas baik & & \\
Y6 & $0.79 *$ PTT & 0.38 & 0.061 & 0.62 & $11.05 * *$ & Validitas baik & \\
\hline
\end{tabular}

Sumber: Data primer diolah, 2019

Secara keseluruhan dapat disimpulkan bahwa hubungan indikator-indikator terhadap variabel karakteristik internal petani dapat dikategorikan baik, karena memiliki nilai composite realiability 0,90 
yang lebih $>$ dari 0,7 , dimana kriteria nilai composite realiability yang baik adalah $>0.7$ dan nilai Variance Extracted (VE), yaitu 0,65.

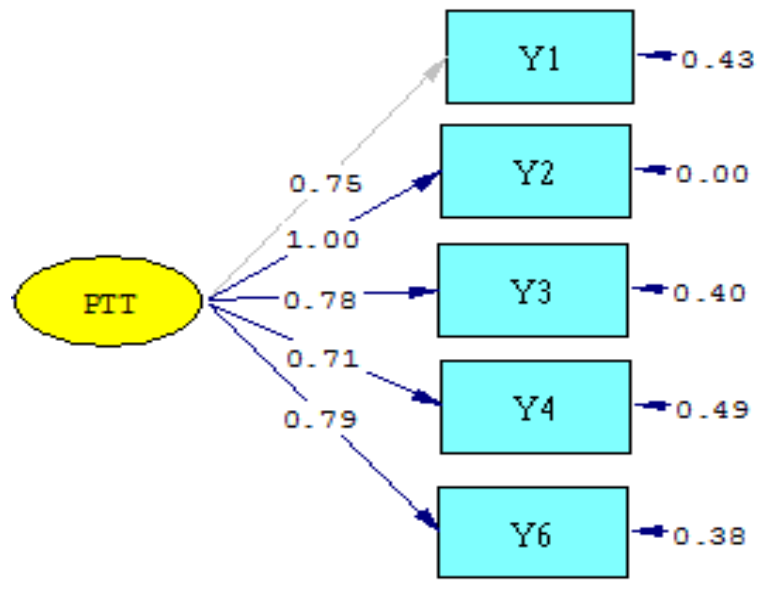

Gambar 3. Nilai muatan faktor $2^{\text {nd }}$ Order CFA

Menurut (Serah 2013), karakteristik inovasi berpengaruh positif terhadap tingkat adopsi inovasi. Suatu inovasi akan diterima bila sebuah teknologi baru memiliki laba, atau semakin besar keuntungan yang dirasakan maka penemuan teknologi semakin mudah diadopsi. Seperti halnya teknologi pengelolaan tanaman terpadu memberikan keuntungan secara finansial terhadap pendapatan petani karena dengan adanya teknologi PTT hasil produksi petani menjadi lebih tinggi. Berbeda dengan studi yang dilakukan oleh (Rozandy, Santoso, and Putri 2012), setelah diuji dengan menggunakan SEM PLS hasil penelitian menunjukkan bahwa tidak terdapat pengaruh yang signifikan antara keunggulan kompetitif dari inovasi dengan tingkat adopsi teknologi.

Berbeda dengan penelitian yang dilakukan oleh (Suharyon, Nurfathiyah, and Wahyudi 2015), faktor yang jadi penentu dan yang berpengaruh nyata terhadap percepatan adopsi inovasi teknologi padi sawah di Kabupaten Sarolangun Jambi terdiri dari pengalaman usahatani padi, jarak lokasi usahatani ke jalan raya, jarak lokasi usahatani pasar input, jarak lokasi usahatani ke pasar output, jarak lokasi usahatani ke sumber teknologi dalam hal ini BPTP dan jarak lokasi usahatani ke kantor penyuluh di Balai Penyuluhan Pertanian. Berdasarkan hasil uji model Goodness of Fit yang telah dilakukan, diketahui ada beberapa kriteria indeks yang dapat menguji model yang digunakan fit atau tidak. Dalam penelitian ini dilihat 9 indeks yang menyatakan bahwa model yang digunakan fit.

Tabel 9. Uji Model Goodness of Fit Test konfirmatori Konstruk Endogen Komponen Teknologi PTT

\begin{tabular}{lccc}
\hline \multicolumn{1}{c}{ Goodness of fit Index } & Cut -off value & Hasil Model & Keterangan \\
\hline$\chi 2-$ Chi-square. & Diharapkan kecil & 25.04 & Fit \\
Df & $>0.00$ & 2 & Good Fit \\
GFI & $\geq 0.90$ & 0.99 & Good Fit \\
TLI/NNFI & $>0,90$ & 0.96 & Good Fit \\
NFI & $>0,90$ & 1.00 & Good Fit \\
CFI. & $>0,90$ & 0.9 & Good Fit \\
IFI & $>0,90$ & 1.00 & Good Fit \\
RMSEA & $\leq 0,08$ & 0.012 & Good Fit \\
RMR & $<0,05$ & 0.034 & Good Fit \\
\hline
\end{tabular}

Sumber: Hasil analisis data primer yang diolah, 2019

\section{Model Persamaan Struktural (Full Model)}

Setelah dilakukan analisis konfirmatori dilakukan dan model dinyatakan fit dengan data, langkah selanjutnya yang harus dilakukan adalah estimasi persamaan struktural secara keseluruhan (full model). Hasil uji kesesuaian model secara keseluruhan dapat dilihat pada Tabel 10 (Halaman 83). Berdasarkan hasil analisis yang telah dilakukan sehingga didapatkan model struktural (full model) dengan memperhatikan nilai eror varian. Hasil analisis regresi memperlihatkan bahwa karakteristik internal petani berpengaruh positif terhadap tingkat adopsi inovasi teknologi PTT dengan nilai 
standardized coeffisient Beta sebesar 0,507 dan nilai signifikan 0,000 artinya terdapat hubungan positif antara karateristik internal petani dengan inovasi pengelolaan tanaman terpadu (PTT).

Tabel 10. Hasil Analisis Model Persamaan Struktural (Full Model) Variabel Laten yang Fit dengan Data

\begin{tabular}{lcccccc}
\hline $\begin{array}{l}\text { Variabel } \\
\text { Manifes }\end{array}$ & Koefisien. Reg & Error.var & Standar Eror & R2 & t.hit & $\begin{array}{c}\text { t.hit } \\
\text { Erorvar }\end{array}$ \\
\hline X1.1 & $0,75 *$ Persepsi & 0,43 & 0,038 & 0,57 & $4,84^{* *}$ & - \\
X1.2 & $0,56 *$ Persepsi & 0,69 & 0,058 & 0,31 & $5,74^{* *}$ & $7,34^{* *}$ \\
X1.3 & $0,82 *$ Persepsi & 0,33 & 0,070 & 0,67 & $6,69^{* *}$ & $3,50^{* *}$ \\
X2.1 & $0,77 *$ Krktr & 0,41 & 0,22 & 0,59 & $1,63 *$ & - \\
X2.2 & $0,98^{*}$ Krktr & 0,04 & 0,51 & 0,96 & $2,33 *$ & 0,088 \\
Y1 & $0,76 *$ PTT & 0,43 & 0,073 & 0,57 & $10,39 * *$ & $8,05 * *$ \\
Y2 & $1,00 *$ PTT & 0,00 & 0,054 & 1,00 & $16,33^{* *}$ & 0,017 \\
Y3 & $0,78 *$ PTT & 0,40 & 0,060 & 0,60 & $10,84^{* *}$ & $7,96^{* *}$ \\
Y4 & $0,71 *$ PTT & 0,49 & 0,067 & 0,51 & $9,62^{* *}$ & $8,16^{* *}$ \\
Y6 & $0,79 *$ PTT & 0,38 & 0,061 & 0,62 & $11,05^{* *}$ & $7,91^{* *}$ \\
\hline Sut
\end{tabular}

Sumber: Data primer diolah, 2019

Keterangan : ** Highly Significant (t hit $>02,61417) \alpha 0,01$

* Significant (t hit > 1.97838) $\alpha 0,05)$

Pengaruh variabel persepsi terhadap inovasi teknologi pengelolaan tanaman terpadu adalah positif dengan nilai standardized solution 0.44 . Hilangnya garis penghubung variabel karakteristik internal petani melalui variabel persepsi terhadap variabel inovasi teknologi pengelolaan tanaman terpadu pada full model dikarenakan variabel tersebut berpengaruh negatif, dengan nilai standardized coeffisient $0,11 .($ Gambar 4)

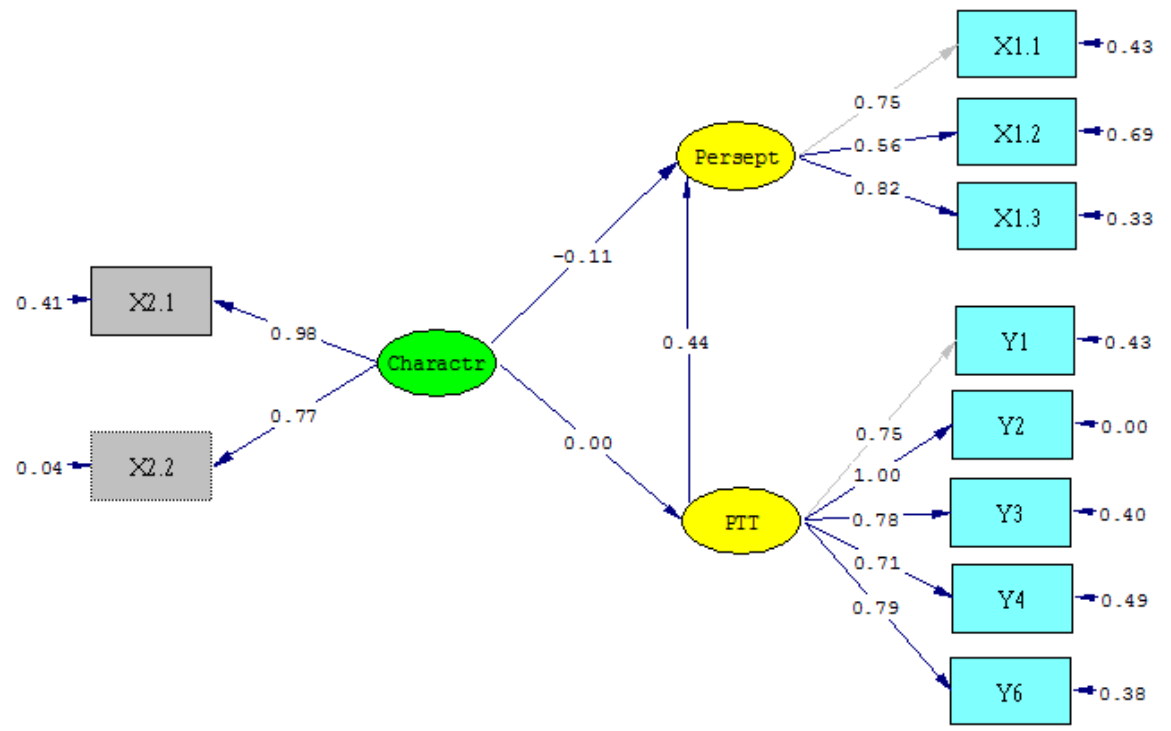

Gambar 4. Nilai muatan faktor $2^{\text {nd }}$ Order CFA.

Sejalan dengan penelitian yang dilakukan oleh (Sudjarmoko et al. 2013) mengenai adopsi benih unggul karet, hasil penelitian mengungkapkan bahwa adopsi benih unggul karet dipengaruhi secara eksklusif oleh harapan petani terhadap produksi benih unggul karet (Product Performance Expectancy/PPE), harga benih unggul karet, dan Social Technical Influence (STI). Berbeda dengan penelitian (Setiawan and Astiti 2017) dimana variabel pengetahuan petani, peluang bisnis, dan motivasi petani memiliki hubungan positif dan signifikan terhadap taraf adopsi menggunakan sistem tanam Jajar Legowo pada Subak Penyaringan, Kabupaten Jembrana. Dengan koefisien determinan (R2) sebesar 0,926.

\section{Hasil Hipotesis}

Dengan melihat hasil yang telah dijelaskan mengenai nilai koefisien regresi, keeratan hubungan $\left(\mathrm{R}^{2}\right)$ dan erorrvar pada Tabel 10. Hasil penelitian menunjukkan bahwa: 
1. Hipotesis H1, menyatakan bahwa adanya hubungan positif antara variabel Y1 (Persepsi) dan variabel Y2 (Pengelolaan Tanaman Terpadu), dari path diagram pada Gambar 4, dapat dilihat bahwa dengan taraf keyakinan $95 \%$ memperoleh nilai t-value sebesar 4.04, sehingga bisa dinyatakan bahwa hipotesis $\mathrm{H} 1$ terbukti atau diterima karena nilai t-value $\geq 1.96$. Maka dapat dinyatakan persepsi petani mengenai inovasi teknologi Pengelolaan Tanaman Terpadu menjadi faktor penentu petani dalam megambil keputusan untuk mengadopsi teknologi PTT.

2. Pengujian hubungan hipotesis $\mathrm{H} 2$ yaitu nilai $t$-value adalah -0.77 (taraf kepercayaan 95\%), menerangkan bahwa hipotesis $\mathrm{H} 2$ tidak terbukti atau ditolak karena nilai $t$-value $\leq 1.96$. Hal ini menunjukkan bahwa hubungan langsung variabel karakteristik internal petani melalui variabel persepsi petani terhadap adopsi teknologi pengelolaan tanaman terpadu adalah tidak signifikan.

3. Hipotesis H3 yaitu terdapat hubungan atau asosiasi positif secara langsung antara variabel X1 (karakteristik internal petani) dan Y2 (pengelolaan tanaman terpadu), hal ini memberitahukan bahwa interaksi yang ada pada hipotesis $\mathrm{H} 3$ adalah signifikan.

\section{KESIMPULAN}

Dapat disimpulkan pada penelitian ini adalah variabel Persepsi Petani terhadap teknologi Pengelolaan Tanaman Terpadu (PTT) menurut sifat teknologi tersebut berada dalam kategori sedang. Tingkat Adopsi teknologi pengelolaan tanaman terpadu (PTT) berada pada kategori sangat tinggi. Artinya mayoritas petani sudah mengadopsi teknologi tersebut dan variabel yang mempengaruhi petani mengadopsi teknologi PTT adalah persepsi petani dengan koefisien sebesar 0,44 terhadap teknologi PTT. Karakteristik Internal Petani tidak mempengaruhi persepsi petani terhadap inovasi teknologi PTT, sebaliknya Karakteristik Internal Petani mempengaruhi Tingkat Adopsi Petani terhadap inovasi teknologi PTT.

\section{UCAPAN TERIMA KASIH}

Ucapan terima kasih disampaikan kepada Kementerian Riset, Teknologi, dan Pendidikan Tinggi, Indonesia yang telah membiayai proyek ini melalui Skema Penelitian Tesis Magister 2019.

\section{DAFTAR PUSTAKA}

Adawiyah, Cut Rabiatul. 2017. "Urgensi KomunikasiDalam Kelompok Kecil Untuk Mempercepat Proses Adopsi Teknologi Pertanian.” Journal Forum Penelitian Agronomi 35(1):59-74. doi: http://dx.doi.org/10.21082/fae.v35n1.2017.59-74.

Anggraeni, R., Dumasari, and Pujiati Utami. 2015. "Kajian Interaksi Sosial Penyuluh Pertanian Dengan Petani Padi Semi Organik Kelompok Tani Jatijaya Desa Sawangan Kecamatan Kebasen Kabupaten Banyumas." AGRITECH XVII(2):144-55.

Badan Litbang Pertanian. 2010. Pedoman Umum PTT Padi Sawah. edited by Kementrian Pertanian Badan Penelitian Dan Pengembangan Pertanian. Jakarta.

Beedell, J., and T. Rehman. 2000. "Using Social-Psychology Models to Understand Farmers' Conservation Behaviour." Journal of Rural Studies 16(1):117-27. doi: 10.1016/S07430167(99)00043-1.

BPS Kabupaten Seluma. 2018. Kabupaten Seluma Dalam Angka 2018. edited by BPS Kabupaten Seluma. Seluma.

Caswell, M., and D. Zilberman. 1985. "The Choices of Irrigation Technologies in California." American Journal of Agricultural Economics 67(224-234). doi: . https://doi.org/10.2307/1240673.

Davis, F. D. 1989. "Perceived Usefulness, Perceived Ease of Use, and User Acceptance of Information Technology." MIS Quarterly 13:319-40. doi: $10.2307 / 249008$ https://www.jstor.org/stable/249008.

Departemen Pertanian. 2016. Pedoman Umum PTT Padi Sawah. 4th ed. edited by Pusat Penelitian Dan Pengembangan Tanaman Pangan. Bogor. 
Fachrista, I. A., and S. Mamik. 2014. "Persepsi Dan Tingkat Adopsi Petani Terhadap Inovasi Teknologi Pengelolaan Tanaman Terpadu Padi Sawah.” Agriekonomika 3(1):1-9.

Farid, Abdul, Ugik Romadi, and Djoko Witono. 2018. "Faktor-Faktor Yang Mempengaruhi Adopsi Petani Dalam Penerapan Sistem Tanam Jajar Legowo Di Desa Sukosari Kecamatan Kasembon Kabupaten Malang Provinsi Jawa Timur." Jurnal Penyuluhan 14(1):27-32. doi: : https://doi.org/10.25015/penyuluhan.v14i1.19226.

Ghozali, Iman. 2008. Model Persamaan Struktural Konsep Dan Aplikasi Dengan Program AMOS16.0. Semarang: Badan Penerbit Universitas Diponegoro.

Hair, J., W. C. Black, B. J. Babin, R. E. Anderson, and R. L. Tatham. 2006. Multivariate Data Analysis. 6th ed. edited by P. P. Hall. New Jersey: Upper Saddle River.

Ismilaili, Ninuk Purnaningsih, and Pang S. Asngari. 2015. "Tingkat Adopsi Inovasi Pengelolaan Tanaman Terpadu (PTT) Padi Sawah Di Kecamatan Leuwiliang, Kabupaten Bogor." Jurnal Penyuluhan 11(1):49-59.

Kline, R. B. 2011. Principles and Practice of Structural Equation Modeling. 3rd ed. New York: The Guilford Press.

Nuthall, P. L. 2001. "Managerial Ability: A Review of Its Basis and Potential Improvement Using Psychological Concepts." Agricultural Economics 24(3):247-62. doi: https://doi.org/10.1016/S0169-5150(00)00069-4.

Pello, Wely Yitro. 2019. "Pengaruh Peran Dan Motivasi Penyuluh Pertanian Terhadap Inovasi Teknologi Budidaya Tanaman Padi Sawah Di Kecamatan Kupang Timur, Kabupaten Kupang Provinsi Nusa Tenggara Timur." Jurnal Penyuluhan 15(2):184-94.

Rahm, Michael R., and Wallace E. Huffman. 1984. "Adoption of Reduced Tillage: The Role of Human Capital and Other Variables." Adoption of Reduced Tillage: The Role of Human Capital and Other Variables. American Journal of Agricultural Economics 66:405-13. doi: http://doi.org/10.1.1.1032.3773.

Riadi, Edi. 2013. Aplikasi Lisrel Untuk Penelitian Analisis Jalur. Yogyakarta: CV ANDI.

Riadi, Edi. 2018. Statistik SEM Structural Equatoin Modeling Dengan LISREL. Yogyakarta: CV ANDI.

Rigdon, Edwar E., and Jr Carl E Ferguson. 1991. "The Performance of the Polychoric Correlation Coefficient and Selected Fitting Functions in Confirmatory Factor Analysis with Ordinal Data." Journal of Marketing Research 28(4):491-97.

Rogers, E. M. 2003. Diffusion of Innovations. 5th ed. New York: Free Press.

Rozandy, R. A., Imam Santoso, and Shyntia Atica Putri. 2012. "Analisis Variabel - Variabel Yang Mempengaruhi Tingkat Adopsi Teknologi Dengan Metode Partial Least Square (Studi Kasus Pada Sentra Industri Tahu Desa Sendang, Kec. Banyakan, Kediri).” Jurnal Industria 1(3):14758.

Serah, Thobias. 2013. "Pengaruh Karakteristik Inovasi Sistem Sosial Dan Saluran Komunikasi Terhadap Adopsi Inovasi Teknologi Pertanian.” Universitas Atma Jaya Yogyakarta.

Setiawan, I. Gd Bagus Dera, and Ni Wayan Sri Astiti. 2017. "Faktor - Faktor Yang Mempengaruhi Adopsi Inovasi Sistem Tanam Jajar Legowo 2: 1 Di Subak Penyaringan Kecamatan Mendoyo, Kabupaten Jembrana." Jurnal Manajemen Agribisnis 5(2):1-6. doi: https://doi.org/10.24843/JMA.2017.v05.i02.p01.

Sharma, A., A. Bailey, and I. Fraser. 2011. "Technology Adoption and Pest Control Strategies among UK Cereal Farmers: Evidence from Parametric and Nonparametric Count Data Models." Journal of Agricultural Economics 62(1):73-92. doi: https://doi.org/10.1111/j.1477-9552.2010.00272.x.

Sudjarmoko, Bedy, Dewi Listyati, and Abdul Muis Hasibuan. 2013. "Analisis Faktor Penentu Adopsi Benih Unggul Karet." Buletin RISTRI, 117-28.

Suharyon, Pera Nurfathiyah, and Erwan Wahyudi. 2015. "Faktor- Faktor Yang Mempengaruhi Jurnal Penyuluhan | Vol. 18 (01) 2022 | 85 
Terhadap Percepatan Adopsi Inovasi Teknologi Ptt Padi Sawah Di Kabupaten Sarolangun Jambi." Jurnal Penelitian Universitas Jambi: Seri Sains 17(2):09-17.

Supriyati, Endang. 2013. "Faktor Adopsi Internet Marketing Untuk Usaha Mikro Dan Usaha Kecil Menengah (UMKM) Di Kabupaten Kudus Dengan Sem (Structural Equation Model) Dan Framework Cobit 4.1." Jurnal Simetris 3(1):1-6.

Wahyu, Harinta Yos. 2010. "Hubungan Sosial Ekonomi Dan Kualifikasi Penyuluh Terhadap Adopsi Teknologi Pengelolaan Tanaman Dan Sumber Daya Terpadu Budidaya Padi (Oriza Sativa)." Jurnal Widyatama 19(2):1-8.

Yartiwi, Ahmad Damiri, and Wawan Eka Putra. 2012. Keragaan Tanaman Padi Berdasarkan Posisi Tanaman Terhadap Komponen Hasil Pada Sistem Tanam Legowo 4:1. edited by Balai Pengkajian Teknologi Pertanian (BPTP). Bengkulu. 